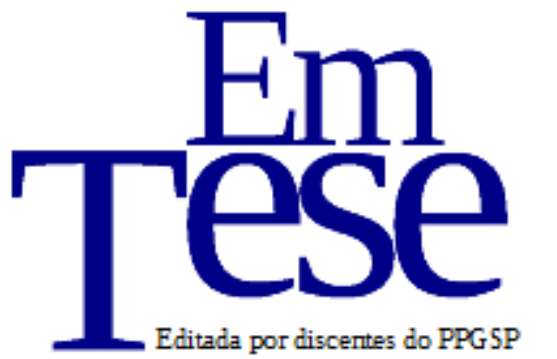

UFSC

PPG SP PROG RAMA DE

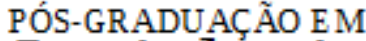

Sociologia

Política

v. 13, n. 1, jan./jun., 2016

\title{
O discurso da mudança de Aécio Neves e Dilma Rousseff: uma análise da prática \\ retórica entre diferentes, no retorno para o segundo turno às eleições de 2014
}

Sandra Regina Barbosa Parzianello ${ }^{1}$

\section{Introdução}

O presente artigo tem por objetivo analisar a batalha discursiva entre diferentes, no retorno para o segundo turno às eleições Presidenciais de 2014, candidato de oposição Senador Aécio Neves ${ }^{2}$ do Partido da Social Democracia Brasileira (PSDB) e a candidata à reeleição Dilma Rousseff ${ }^{3}$ do Partido dos Trabalhadores (PT). O universo teórico epistemológico que propomos neste trabalho se insere na Teoria do Discurso, com base no pensamento desenvolvido pelo teórico-político, Ernesto Laclau ${ }^{4}$, conforme os recursos discursivos que intervém na construção política pelo domínio da retórica, uma das categorias fundamentais e de abordagem na dinâmica política.

De acordo com nossa compreensão, o uso de termos figurativos, por vezes

${ }^{1}$ Bel. em Ciências Sociais - Ciência Política (Unipamp), Mestranda do Programa de Pós-graduação em Ciência Política da Universidade Federal de Pelotas (UFPel), RS. Email: parzianellos@yahoo.com.br. 2Coligação "Muda Brasil”, formada pelos partidos: PSDB, SD, PMN, PEN, PTN, PTC DEM, PTdoB e PTB. Para o segundo turno, apoiam o candidato, a terceira colocada do primeiro turno, Marina Silva (PSB), bem como os partidos: PPS, PV (e seu candidato à presidência, Eduardo Jorge), o PSC (e seu candidato à presidência, Pastor Everaldo), o PSDCe o PRTB (e seu candidato a presidênciaLevy Fidelix). 3Coligação "Com a Força do Povo”, formada pelos partidos: PT, PMDB, PSD, PP, PR, PDT, PRB, PROS e PCdoB. A candidata não atraiu para si muitos apoios ao segundo turno, apenas a candidata a presidência, Luciana Genro (PSOL), sugeriu à militância votar branco, nulo, ou em Dilma Rousseff (PT). O PSTU optou pela neutralidade, e recomendou o voto nulo.

406 de outubro de 1935 - 13 de abril de 2014: foi um argentino, teórico político, também descrito como pós-marxista. 
empregados, e, que desviam o foco do debate político, nada mais representa do que uma carência retórica se considerar os temas essenciais à campanha, sob a falta de um discurso ${ }^{5}$ propositivo e enquanto instrumento fecundo à possibilidade de uma democracia representativa. Conforme Laclau: "Ocorre um deslocamento retórico toda vez que um termo literal é substituído por um termo figurativo.” (2013, p. 120).

A noção de deslocamento apresenta-se como "um bloqueio constitutivo da linguagem, que requer nomear algo essencialmente inominável como uma condição para o próprio funcionamento da linguagem" (LACLAU, 2013, p. 120-121). Veremos ao longo deste trabalho que a forma como a política está organizada é momentânea e contingente, pois depende de um universo de sentidos fundado na forma e em como o campo discursivo está estruturado ${ }^{6}$, aplicações e novas reflexões políticas que estão no interior da Teoria do Discurso.

Ernesto Laclau direcionou os estudos e a reflexão no sentido de discutir e abrir caminhos à compreensão de um tipo distinto de análise do discurso ${ }^{7}$ e a ideologia, situando hegemonia, política, significantes vazios e flutuantes, identidades diferenciais e outros sentidos articulados ao contexto investigativo. Sua teoria, pós-estruturalista, move-se pelo trabalho que sugere explicar a realidade, a contemporaneidade com análises inovadoras sobre concretos fenômenos políticos.

Assim, sabendo que na política todas as ações discursivas são práticas significativas, porque movimentam o desejo pelo poder, comparamos o emprego de práticas que dão sentido e atribuem sentidos, conforme a contingência do momento histórico. Vejamos o emprego do discurso da "mudança", no retorno ao segundo turno, entre identidades diferenciadas, empregos diferenciados a partir de alguns recortes extraídos do Horário Gratuito de Propaganda Eleitoral ${ }^{8}$ (HGPE). De um lado, o discurso da "mudança" da coligação "Muda Brasil", que aposta na não continuidade do governo petista, sustentado pela "imensa vontade de mudança do povo brasileiro". De outro lado, o discurso da "mudança" da coligação "Com a Força do Povo" sob o refrão "Governo novo, ideias novas" em defesa de um programa que representa um "futuro", um reforço

5“(...) quaisquer conjuntos de elementos nos quais as relações desempenham o papel constitutivo" (LACLAU, 2013, p. 116).

6 No sentido de guiar as ações.

7Orientação teórica e analítica reconhecida atualmente como o "Essex Escola de análise do discurso". 8Em 09 de outubro de 2014, início do HGPE para o segundo turno. 
às novas ideias para a continuidade do governo.

\section{Vislumbres entre os diferentes}

O discurso de campanha dos candidatos Aécio Neves (PSDB) e Dilma Rousseff (PT) no retorno ao segundo turno em HGPE foi gerador de ataques mútuos, mais pontualmente ataques ao projeto de governo adversário, numa verdadeira batalha discursiva entre oposição e governo, e, em torno do tema economia no que diz respeito à recuperação e estabilidade econômica que ao longo do texto, portanto, voltaremos a abordar.

Dentro dessa linha, destaca-se a abordagem significativa à análise do discurso, que é a noção de articulação. Ernesto Laclau e Chantal Mouffe (2015) entendem qualquer prática que estabeleça a relação entre elementos de tal forma que suas identidades sejam modificadas, éresultado da prática articulatória, portanto, não há lógica anterior à lógica da articulação. O discurso nada mais é do que o resultado da articulação dos momentos diversos.

Ambos os candidatos deixam claro que a disputa será acirrada, e, cada um a seu modo tenta convencer o eleitor de que representa a "mudança". Nesta chegada ao segundo turno, Aécio e Dilma configuram mais uma vez um quadro de solidez e certa tradição para a polarização política no Brasil, cada vez mais radical, que os eleitores delegam e aprovam através do voto, pelo menos nos últimos 20 anos. Em comparações entre governos PT e PSDB, os candidatos dão destaque à economia e fecundam uma desconstrução do projeto de governo adversário; a emergência do momento histórico "impôs" aos candidatos uma linguagem a fim de convencer o eleitor de que representam a "mudança", conforme podemos ver na transcrição dos discursos:

Entendi o recado das ruas e das urnas. Os brasileiros e as brasileiras que me deram o voto disseram que a melhor forma de continuar mudando é acelerar e aperfeiçoar o que está em andamento e fazer um governo novo, com ideias novas (ROUSSEFF, HGPE, 09/10/2014).

O candidato de oposição deu enfoque ao termo "mudança" refletida no próprio nome da coligação: "Muda Brasil". 
Quero começar este segundo turno das eleições dando parabéns ao grande vitorioso do último domingo, que foi você. Quem venceu de verdade foi à imensa vontade de mudança do povo brasileiro. Milhões de brasileiros deixaram claro que não aceitam mais que o Brasil continue no caminho que está (NEVES, HGPE, 09/10/2014).

Oportunamente, Aécio fez menção aos eleitores da ex-candidata Marina Silva (PSB), e afirmou: "Quem não votou em mim, mas votou na mudança, convido agora a vir com a gente".

Esse desejo de "mudança" paralelo à articulação ${ }^{9}$ e ao movimento político representa, basicamente, uma essência na constituição de um inimigo e um momento ${ }^{10}$ de possibilidade para a construção políticodiscursiva que justifica “(...) a necessidade de expressar algo que o termo literal simplesmente não transmitiria. Nesse sentido, a catacrese é mais do que uma figura particular: é o denominador comum da retórica ${ }^{11}$ enquanto tal" (LACLAU, 2013, p.121).

Os discursos constituídos por posições políticas diferentes que, segundo Laclau (2015), não se estruturam mais em torno de uma divisão social, mas se estabelecem por uma nova concepção de hegemonia ${ }^{12}$, “(...) requer a criação de novas fronteiras políticas, não seu desaparecimento" (LACLAU, 2015, p. 43). Desta forma, cada candidato se apropria do uso da linguagem figurativa enquanto parte do discurso político ${ }^{13}$, portanto, uma ferramenta para a compreensão do social, em favor da promoção de sentido a um número maior de pessoas, que encontram no uso da retórica a satisfação, ainda que imaginária e discursiva, às diferentes e diversas demandas ${ }^{14}$.

O discurso político é o discurso por excelência do sujeito em todos os

9Numa tentativa de homogeneizar a sociedade.

10 As posições diferenciais na medida em que elas aparecem articuladas dentro do discurso, nós chamamos de momento (LACLAU e MOUFFE, 1985, p. 105).

11 “(...) usar palavras em mais de um sentido, desviando-as de seu significado literal, primordial” (LACLAU, 2013, p. 120).

12 “(...) refere-se à capacidade que uma demanda demonstre de interpelar um conjunto de outras demandas, de tal maneira que elas se reconheçam como parte daquela. Trata-se de um processo de universalização do particular"(BURITY, 2014, p.71).

130 discurso político está aqui sendo entendido como aquele que reivindica o poder público (o Estado) através da construção de uma visão de mundo que se apresenta como a visão dos interesses gerais da sociedade (PINTO, 1989, p.51).

14“(...) o conceito de "demanda” (demand) é ambíguo: pode significar uma solicitação, mas também pode significar uma exigência, por exemplo 'exigir uma reivindicação'. Essa ambiguidade de significado, porém, é útil para nossos propósitos, pois é na transição da solicitação para a exigência que iremos encontrar um dos primeiros traços do populismo" (LACLAU, 2013, p. 123).

UFSC, Florianópolis - http://dx.doi.org/10.5007/1806-5023.2016v13n1p6 ISSN: 1806-5023 
seus sentidos, seu local de enunciação é a luta política, seu objetivo é vencer a luta através do jogo de desconstrução e reconstrução de significados, interpelado através da construção articulada de uma visão de mundo. (PINTO, 1989, p. 51-52).

A verdadeira política não se preocupa necessariamente com uma plataforma clara e objetiva. O que se apresenta são uma multiplicidade e diversidade de emergências que se traduzem em objetos empíricos, o que permite a possibilidade de análise sobre a constituição de um vazio teórico onde se tem a desconstrução de um pensamento e se recoloca a análise como um elemento ${ }^{15}$ complicador, que são as relações de poder.

Um significante vazio é, no sentido estrito do termo, um significante sem significado. Esta definição é também a enunciação de um problema. (...) um significante vazio seria uma mera sequência de sons e, se este é desprovido de qualquer função significativa, o termo "significante" se tornaria, nesse caso excessivo. (LACLAU, 2011, p. $67)$.

No processo eleitoral o discurso da "mudança" está entre o funcionamento estrutural e a relação entre governo e governado com um fim específico que se resume a gestão do Estado. A produção ${ }^{16}$ social dos significantes vazios na concepção laclauniana considera a contingência e a articulação das ações, movidas pelo discurso. Conforme Laclau, os limites são sempre antagônicos ${ }^{17}$ na relação política, em que o papel da retórica é a possibilidade de discurso que tem uma origem e um fundamento próprio para justificar sua possibilidade de existência.

As propostas políticas e antagônicas são parte da construção da política, explicada pelo jogo das diferenças, e a campanha eleitoral é um momento de promoção da identificação. No jogo a sociedade força-se a identificar inimigos e a reintroduzir um discurso de divisão social, baseado em lógicas de equivalência ${ }^{18}$, resultado das demandas identificadas no estabelecimento e constituição dessa sociedade.

15 Por contraste, nós chamamos de elemento qualquer diferença que não seja discursivamente articulada(LACLAU e MOUFFE, 1985, p. 105).

16Que só tem sentido em um sistema concreto de relações sociais, conforme Laclau e Mouffe (2004,p. 135).

17“Antagonismo é a luta entre inimigos (...)” (MENDONÇA, 2003, p. 140).

18“A equivalência, porém, é precisamente aquilo que subverte a diferença, e assim toda identidade é construída no bojo da tensão entre a lógica da diferença e a lógica da equivalência" (LACLAU, 2013, p. 119). 
Para desconstruir o inimigo PSDB, o PT usou já no primeiro programa do segundo turno, a mesma estratégia de desconstrução usada contra Marina Silva (PSB) no primeiro turno. Usando termos como "retrocesso", o partido criticou o projeto dos tucanos em oposição ao programa petista, que representa o "futuro". A candidata petista disse que "não faz ataques pessoais ao adversário", em compensação criticou duramente o partido.

Dilma Rousseff destacou:

Ele [Aécio] representa o modelo que quebrou o país três vezes, abafou todos os escândalos de corrupção, privatizou o patrimônio público a preço de banana, causou desemprego altíssimo, arrocho salarial e recessão, se curvou ao FMI, esqueceu os mais pobres, não investiu nem na área social, nem na infra-estrutura. (ROUSSEFF, HGPE, 09/10/2014).

A candidata também fez uma associação entre os tucanos e o discurso de "apatia, distância, insensibilidade e conformismo", relacionando com a figura do ex-presidente Fernando Henrique Cardoso (FHC), e a frase por ele usada, que representaria "o estilo tucano de encarar o Brasil”. O programa eleitoral reforçou:

Quando era presidente, ele [FHC] chegou a chamar os aposentados de vagabundos. Agora, ao comentar o primeiro turno desta eleição, ele disse literalmente: 'Não é porque são mais pobres que votam no PT, mas porque são menos informados". Ou seja, para FHC, os 43 milhões de eleitores de Dilma são ignorantes. (HGPE, 09/10/2014).

Durante a propaganda a candidata petista admitiu que a economia passa por "dificuldades momentâneas" e vagamente reconheceu que é preciso fazer "mudanças" neste setor através do controle da inflação com "mais firmeza", mas seguiu na comparação, como trunfo eleitoral, a administração FHC que desempregou e comprometeu a renda com arrocho salarial. Segundo Laclau (2011) uma mobilização parcial não está determinada por nenhuma consideração teórica a cerca da prioridade respectiva das lutas políticas ou econômicas.

Apesar de abstrato, enquanto objeto, a instabilidade social e econômica ganham uma condição discursiva de existência e de centralidade. Trata-se neste viés de um campo de sobredeterminação e de variação contingente e limitada, por isso, tão importante para a política, frente a uma determinação essencial, inerte às eleições. Entre 
as variações e acontecimentos que corroboram para determinar a identidade, o programa petista segue afirmando: "Nos governos tucanos, o Brasil chegou a ser o segundo país do mundo com o maior número de pessoas desempregadas. Com o governo Dilma, temos as menores taxas de desemprego da nossa história e uma das menores do mundo".

Contudo, parece claro que, nesse caso o significante não seria vazio, mas equívoco: em cada contexto, a função de significação se realizaria plenamente. Uma segunda possibilidade seria que o significante não fosse equívoco, mas ambíguo: que tanto uma sobredeterminação ${ }^{19}$ quanto uma subdeterminação de significados impediriam fixá-lo plenamente. (...) não enfrentamos excesso ou deficiência de significações, mas a exata possibilidade teórica de algo que aponte, do interior do processo de significação, a presença discursiva de seus próprios limites. (LACLAU, 2011, p. 68).

A propaganda de Dilma reforça as conquistas do PT no primeiro turno, com presença de governadores e senadores eleitos tanto pelo partido como pela base aliada. Para reforçar a ideia o governador eleito de Minas Gerais, Fernando Pimentel, foi o primeiro a aparecer, dando um sentido ainda maior a fala da candidata: "Tivemos uma importante vitória. Tivemos mais votos em Minas, território do adversário", disse a petista. O que estabelece essa unidade, segundo a teoria de Laclau, não é algo positivo que é dividido entre os membros, mas algo "negativo" - a oposição a um inimigo comum.

Aécio Neves aposta no movimento da "mudança" com uma propaganda que também desconstrói e que marca oposição ao governo PT, um governo que "não funciona" e que os brasileiros não teriam mais "confiança no seu próprio futuro". O candidato fortalece o significado ao afirmar: "Quando o governo é o problema, a vida de todo mundo vira também problema. A educação, a saúde, a segurança, a inflação, tudo vira problema. Queremos de volta os bons valores que sempre tivemos", construindo a seu favor a possibilidade de governo.

Se desigualar do inimigo é não só especificar-se na diferença, como também buscar uma legitimidade junto ao eleitor, que baseado na desigualdade imagina encontrar o diferente, a fim de conquistar um espaço em que a disputa é acirrada. (LACLAU, MOUFFE, 2004, p. 134). 
Desconstruir o oponente marca uma necessidade de destacar positivamente o que o distingue, mesmo que de forma impactante e incisiva. Com este intuito, a propaganda do PSDB procura apresentar o candidato ao eleitor, mostrando sua trajetória política e, principalmente, a relação com o avô Tancredo Neves, num recurso de repetição. Este certo "desespero" discursivo é uma busca de legitimação, um fenômeno identificado já na antiguidade ${ }^{20}$, mas de característica contemporânea, em meio ao desgosto do que temos e ao gosto do que ainda não possuímos.

A campanha eleitoral tornou-se um preparo para o evento maior, o encontro com o real democrático que se consolida nas urnas, com as eleições. $\mathrm{O}$ desajuste promovido pelo discurso é resultado de uma construção que é retroativa a todo este processo que se desencadeia e que conforme a teoria, "os verdadeiros limites são sempre antagônicos" (LACLAU, 2011, p. 69). Essa perspectiva é confirmada no discurso e na premissa do candidato Aécio ao reforçar que a disputa no segundo turno será árdua: "A luta vai ser dura. Nossos adversários já mostraram que não têm limites quando o que está em jogo é o seu projeto de poder". Laclau aponta:

Operar na lógica dos limites excludentes tem uma série de efeitos
necessários que se estendem a ambos os lados do limite e nos
conduzem de modo direto à emergência dos significantes vazios: 1 .
(...) Por um lado, cada elemento do sistema só tem uma identidade, na
medida em que é diferente dos outros: diferença = identidade. Por
outro lado, todas essas diferenças são equivalentes umas as outras, na
medida em que pertencem ao lado interno da fronteira de exclusão. (...)
2. (...) a possibilidade de um significante vazio anunciando a si
mesmo por meio dessa lógica em que as diferenças se dissolvem em
cadeias equivalências. 3. (...) A resposta é que estamos tentando
significar nos limites da significação - o Real, como dizemos no
sentido lacaniano - e não há um modo de fazê-lo diretamente, exceto
por meio da subversão do processo de significação. (LACLAU, 2011,
p. 69-71).

Assim os efeitos nocivos da polarização podem colaborar com os diferentes, que estão sempre em comparação, ou criar impossibilidades discursivas cada vez mais importantes no espaço, entre o deslocamento e a estrutura com certa liberdade, que acentuam ainda mais os discursos que se antagonizam. Antagônicos entre si e entre o poder. Neste sentido podemos sugerir um exemplo na propaganda do PSDB, conforme 20Numa referência a "A República", de Platão. 
vimos no seguinte trecho: "Dilma pegou um país que ia bem e que, quatro anos depois, está em recessão. Parado. Aécio pegou um estado que ia mal e que, dois anos depois, voltou a crescer".

Assim, sustenta-se que um mesmo significante pode ser vinculado a distintos significados em diferentes contextos. Esta afirmação leva, porém, a um equívoco e não necessariamente a um significante vazio, devido à contingência e a compreensão dessa dimensão contextualizada.

O HGPE também abre para alguns inúmeros paralelos entre os diferentes. A propaganda afirmou que Aécio teria cortado o número de secretarias e cargos políticos durante seu governo em Minas Gerais, enquanto Dilma havia ampliado a quantidade de ministérios. É preciso dizer que, quanto mais o discurso se repete, mais se cristaliza, logo, mais se universaliza, porém, ainda que articulado o discurso corre o risco de cair em um momento de ressignificação e produção de sentidos de acordo com o momento, em meio a tantas demandas. A comparação continuou: "Dilma diz que a culpa dos problemas do Brasil é do mundo. Aécio diz que a culpa é do governo. Dilma diz que é preciso continuar como está. Aécio diz que é preciso mudar. O que você prefere? Mudar com Aécio ou ficar com Dilma?".

Para tornar ainda mais significativo o que o candidato do Partido da Social Democracia Brasileira(PSDB) representa, o segundo turno abre um discurso de caráter persuasivo e contingente, em que o diferencial está na valorização dos apoios dados à candidatura de Aécio. Somam-se a coligação os ex-candidatos Pastor Everaldo do Partido Social Cristão (PSC) e Eduardo Jorge do Partido Verde (PV), bem como o Partido Popular Socialista (PPS) e o Partido Socialista Brasileiro(PSB).

A propaganda ainda destaca o Partido Socialista Brasileiro(PSB) e um contingente de seus militantes, junto ao candidato Aécio em discurso afirmando se sentir "emocionado", e segue: "Passo a ter a responsabilidade de, no limite das minhas forças, levar, pelo Brasil inteiro, o legado de Eduardo Campos”. A partir deste trecho, nossa análise prática foca no processo de produção, consumo e adequação textual em que o discurso é gerado. Nota-se que forçar um sentido extralinguístico, como da emoção, torna-se um caminho político arriscado à produção de sentidos em que o significado das palavras abrem espaço a multiplicidade de articulações com uma definição que não se estabiliza e, portanto, não permite um sentido unívoco. 


\section{Considerações finais}

Nossas considerações emergem no sentido da possibilidade e importância de um espaço cada vez maior para a análise e reflexão dos fatos na contemporaneidade. Ernesto Laclau apresenta a possibilidade de análise da lógica de formação das identidades políticas, a articulação de elementos ao debate e a consideração de postulados teóricos, entre os quais podemos citar os significantes vazios, a hegemonia, o discurso e a retórica.

Na política, de modo especial, a complexidade de determinadas questões desafia práticas e a funcionalidade do trabalho teórico reflexivo. Com o tratamento laclauniano, descobrimos que toda a forma de poder se constrói, em suas concepções e novas reflexões paradoxais, em que se considere um momento propositivo, somadas às ponderações lógicas que crescem naqueles adeptos e curiosos a sua linha de pensamento contemporâneo.

Laclau revela-se arrojado em sua concepção, constrói e desconstrói uma ideia pelo raciocínio e sob a credencial de suas categorias que apontam ao contexto discursivo e as condições de emergência. Em Laclau "a política é possível porque a impossibilidade constitutiva da sociedade só pode representar a si mesma por meio da produção de significantes vazios" (2011, p. 78). Para Laclau tudo é discurso, pois tudo o que conhecemos tem um nome e sentido.

\section{Referências}

LACLAU, Ernesto. "La impossibilidad de la sociedad". In: . Nuevas reflexiones sobre la revolución de nuestro tiempo. Buenos Aires: Nueva Visión. 1993. 103-106p.

.Emancipação e Diferença. Rio de Janeiro: EdUERJ, 2011.

A razão populista. São Paulo: Três Estrelas, 2013. 
LACLAU, Ernesto e MOUFFE, Chantal. "Beyond the positivity of the social: antagonisms and hemony". In: . Hegemony \& socialist strategy:

Towards a radical democratic politics. London: Verso, 1985. 93-148p.

Hegemonia y estrategia socialista. $2^{\mathrm{a}}$ ed. Buenos Aires: FCE, Argentina, 2004.

Hegemonia e estratégia socialista por uma política democrática radical.

São Paulo: Intermeios; Brasília: CNPq, 2015.

MENDONÇA, Daniel de. A noção de antagonismo na ciência política contemporânea: uma análise a partir da perspectiva da teoria do discurso. Revista de Sociologia e Política, Curitiba, jun. 2003, n. 20, p. 135-145.

NEVES, Aécio. HGPE, 09/10/2014. Disponível em: http://www.youtube.com/watch?v=LZRwduEgJJM.

PINTO, Céli Regina Jardim. Com a palavra o senhor presidente José Sarney: o discurso do Plano Cruzado. São Paulo: Editora Hucitec, 1989.

ROUSSEFF, Dilma. HGPE, 09/10/2014. Disponível em: http://www.youtube.com/watch?v=aQi4-Vv62RM.

O discurso da "mudança” de Aécio Neves e Dilma Rousseff: uma análise da 
prática retórica entre diferentes, no retorno para o segundo turno às eleições de 2014

Resumo: O objetivo do artigo é analisar a batalha discursiva entre diferentes candidatos à Presidência da República, Aécio Neves (PSDB) e Dilma Rousseff (PT), no Horário Gratuito de Propaganda Eleitoral (HGPE) no retorno para o segundo turno das eleições de 2014. De um lado, o discurso da "mudança", da coligação "Muda Brasil", contrário ao governo petista e, a partir de então, sustentado pela "imensa vontade de mudança do povo brasileiro". De outro lado, o discurso da "mudança" com o refrão "Governo novo, ideias novas" em defesa de um programa que representa o "futuro". Propomos trabalhar com os dados comparativos, destacados pelos próprios candidatos, que fecundam do tema economia e da desconstrução do projeto de governo adversário, conforme os recursos discursivos que intervêm na construção política pelo domínio da retórica, uma das categorias fundamentais para a abordagem teórica de Ernesto Laclau.

Palavras-chave: Eleições 2014; Discurso; Ernesto Laclau.

\title{
The discourse of "change" of Aécio Neves and Dilma Rousseff: an analysis of rhetorical practice between different, in return for the second round the 2014 elections
}

\begin{abstract}
The purpose of the paper is to analyze the discursive battle between different candidates for the Presidency, Aécio Neves (from PSDB party) and Dilma Rousseff (from PT party), at the Free Election Propaganda Time (in a free translation of HorárioGratuito de Propaganda Eleitoral in portuguese), coming back for the 2014 election runoff. On one hand, the discourse of "change" from "Muda Brasil" coalition, opposing to the PT government and, thereafter, sustained by the "Brazilian people's urge to changes." On the other hand, the discourse of "change" with the refrain "New government, new ideas" supporting a program that represents the "future". We propose to work with comparative data, highlighted by the candidates themselves, which fertilize the economy theme and the adversary government's project of deconstruction, as the discursive resources that intervene in the political construction through rhetoric,
\end{abstract}


one of the key categories to the theoretical approach of Ernesto Laclau.

Keywords: Elections 2014; Speech; Ernesto Laclau.

Recebido em: 22 de outubro de 2014.

Aceito para publicação em: 28 de março de 2016. 